\title{
Optimization of Factors Influencing Agrobacterium mediated Genetic Transformation in Eclipta alba (L.) Hassk.
}

\author{
Shruti Bardar, S.L. Kothari ${ }^{1}$ and Sumita Kachhwaha* \\ Department of Botany, University of Rajasthan, Jaipur, India-302 004, India \\ Keywords: Eclipta alba, Nodal segments, Genetic transformation
}

\begin{abstract}
An efficient and reproducible protocol for in vitro plant regeneration and Agrobacterium-mediated genetic transformation was developed for Eclipta alba (L.) Hassk. using nodal explants. Several parameters affecting Agrobacteriummediated gene delivery were investigated and optimized. These include antibiotic concentration, preculture period, infection time, use of acetosyringone, co-cultivation period and temperature and increased level of copper in induction, co-cultivation and regeneration medium. Incorporation of elevated level of $\mathrm{CuSO}_{4}$ led to significant improvements in plant regeneration and recovery of transformed plants. The highest frequency of transformation was observed when explants were infected and co-cultivated at $23^{\circ} \mathrm{C}$. Higher transformation frequency was attained by augmenting the medium with $1.0 \mu \mathrm{M}$ $\mathrm{CuSO}_{4}$ which was ten times the normal MS level. Addition of acetosyringone in the infection and co-cultivation media was very beneficial and resulted in greater transformation efficiency. Transient and stable expression of gus gene was confirmed with histochemical assay of infected explants and leaves of regenerated transformants, respectively. Molecular analysis of transformed plants with nptII and gus A specific primers revealed the amplification of $n p t I I$ and gus gene thereby demonstrated the efficacy of optimized protocol for $A$. tumefaciens-mediated genetic transformation in Eclipta alba for the first time.
\end{abstract}

\footnotetext{
*Author for correspondence: <kachhwahasumita@rediffmail>. ${ }^{1}$ Amity University

Rajasthan, Jaipur, India.
} 


\section{Introduction}

Annual herbaceous plant Eclipta alba (L.) Hassk. (Asteraceae) is also known as 'Bhringraj' or 'False Daisy'. This natural weed native to tropics and subtropics is well known for its medicinal values in alternative systems of holistic health and herbal medicine. Besides blackening and promoting hair growth, antiageing, hepatoprotective, antihyperglycemic, antidiabetic, anti-inflammatory, antioxidant and antimicrobial activities of the plant have also been well documented (Jadhav et al. 2009). Pharmacological investigations have revealed association of hepatoprotective property mainly due to two active constituents, wedelolactone and demethylwedelolactone (Franca et al. 1995).

Although E. alba can be propagated through seeds, but natural and premeditated habitat destruction causes uneven seed distribution and germination which limits its availability. Small seed size and heavy insect/nematode infestation of seedlings leads to massive plant damage resulting in reduction of healthy plant population. Therefore, genetic transformation of E. alba is required for introduction of important traits such as higher yield, increased resistance to pathogens, stress tolerance, enhancing secondary metabolite production, oil content and induce changes in the oil composition.

There are several reports on in vitro plant regeneration of E. alba (Franca et al. 1995, Borthakur et al. 2000, Baskaran and Jayabalan 2005, Dhaka and Kothari 2005, Singh et al. 2012, Bardar et al. 2014). Significant improvements in shoot bud induction and proliferation was also observed by using elevated $\mathrm{CuSO}_{4}$ in culture media (Bardar et al. 2014). But none of the reports mentioned about efficient transgenesis via Agrobacterium tumefaciens. Hence, this improved and modified regeneration protocol is very imperative as it is not only the first successful attempt to achieve in vitro transgenesis via A. tumefaciens, but also highlighted the positive role of elevated $\mathrm{CuSO}_{4}$ for attaining greater transformation efficiency.

\section{Material and Methods}

Plant collection and explant culture, induction and proliferation of shoot buds, rooting and field transfer of plant and genetic fidelity assessment was done as reported previously by Bardar et al. (2014).

The A. tumefaciens strains LBA 4404 with plasmid pBI-121 and EHA-105 with plasmids pCNL-56 and p35S-GUS-INT (Vancanneyt et al. 1990) (Fig. 1) possessing nptII gene as selectable marker conferring resistance against kanamycin and the $u i d A$ (gus) reporter gene under CaMV 35S promoter were used in the study to select the most suitable strain for transformation. 
Sensitivity of the nodal explants for kanamycin was determined by culturing nodes on two different media - control/normal regeneration media (CRM/NRM) containing MS + Kn $(2.0 \mathrm{mg} / \mathrm{l})$ and modified/improved regeneration media $(\mathrm{MRM} / \mathrm{IRM})$ containing MS with $1.0 \mu \mathrm{M} \mathrm{CuSO}_{4}(10$ times the normal MS level) + $\mathrm{Kn}(2.0 \mathrm{mg} / \mathrm{l})$. Each medium was supplemented with different concentrations of kanamycin $(0,10,20,30,50,75,90$ and $100 \mathrm{mg} / \mathrm{l})$.

Nodal segments $(0.5-1.0 \mathrm{~cm})$ were precultured on two different mediaNRM and IRM in conical flasks for 3 - 9 days.

A. tumefaciens strain EHA105 harboring plasmid p35S-GUSINT (Fig. 1) was grown in yeast extract mannitol medium (YEM) (Vincent 1970) with kanamycin $(50 \mathrm{mg} / \mathrm{l})$ and rifampicin $(20 \mathrm{mg} / \mathrm{l})$ at $28^{\circ} \mathrm{C}$ overnight in an incubator shaker (Orbitek, India) with continuous shaking (220 rpm), to an optical density of 0.5 , $0.8,1.0$, or 1.5 at $600 \mathrm{~nm}$. Bacterial cells were centrifuged at 5,000 rpm for $7 \mathrm{~min}$. and resuspended in liquid MS to $0.8 \mathrm{OD}$.

Nodal explants pre-cultured for 3, 5, 7 and 9 days on the both media were pricked with a needle and immersed in an A. tumefaciens suspension for 10, 20, 25, 30, 3545 and 60 mins with gentle shaking. After infection, nodal explants were blotted dry on sterile filter paper. Explants were then transferred to antibiotic free cocultivation medium [(MS with $1.0 \mu \mathrm{M} \mathrm{CuSO}_{4}+\mathrm{Kn}(2.0 \mathrm{mg} / \mathrm{l})+$ $\left.\mathrm{GA}_{3}(0.5 \mathrm{mg} / \mathrm{l})\right]$ supplemented with acetosyringone and cultured in the dark at 26 $\pm 2^{\circ} \mathrm{C}$ for 2-8 days. The regeneration potential of nodal explants after cocultivation with Agrobacterium was evaluated in two different media- NRM and IRM containing cefotaxime $(325 \mathrm{mg} / \mathrm{l})$ and kanamycin $(50 \mathrm{mg} / \mathrm{l})$ for selection of transformed shoots. Each medium was supplemented with $\mathrm{GA}_{3}(0.5 \mathrm{mg} / \mathrm{l})$, sucrose $(30 \mathrm{~g} / \mathrm{l})$ and agar $(9 \mathrm{~g} / \mathrm{l})$. $\mathrm{pH}$ was adjusted to 5.8 before autoclaving at $121^{\circ} \mathrm{C}$ for $18 \mathrm{~min}$. Antibiotics were filter sterilized and added to media before use. The cultures were subcultured on the same medium at 15 days intervals. After three cycles of selection, elongated shoots were subjected to rooting media and after rooting were finally transferred to controlled greenhouse conditions.

The effect of variable concentrations of acetosyringone (AS) was also tested on infection and co-cultivation medium. Different concentrations of AS $(0,20,50$, 80,100 and $150 \mu \mathrm{M}$ ) were added to the infection medium. The infected explants were transferred on co-cultivation medium containing different concentrations of AS $(0,20,50,80,100$ and $150 \mu \mathrm{M})$.

Agrobacterium-infected nodal explants were tested for transient $\beta$-glucuronidase (GUS) expression after 5th and 7th day of co-cultivation (Jefferson 1987), and stable GUS expression was tested in regenerated shoots. Infected explants (after co-cultivation) and regenerated putative transformants and their parts like leaves and roots were checked for GUS expression by placing them in Eppendorf 
tubes containing GUS-buffer (1 mM 5-bromo, 4-chloro, 3 indolyl-D-glucuronide (XGluc), $100 \mathrm{mM}$ sodium phosphate buffer $\mathrm{pH}$ 7.0, $0.5 \mathrm{mM}$ potassium ferricynide, $0.5 \mathrm{mM}$ potassium ferrocynide, and $0.1 \%$ triton $\mathrm{X}-100$ ). They were incubated overnight at $37^{\circ} \mathrm{C}$, washed once with sterile DW and finally dipped in $70 \%$ ethanol overnight to remove chlorophyll and other pigments prior to photography and visual analysis. Per cent GUS expression was calculated as number of explants expressing the GUS/number of explants infected.

DNA was isolated from putative transformants and control shoots of E. alba using a Qiagen mini DNA kit (Genetix Biotech, Bangalore, India). Desalted gus A gene specific primers of OD 3.0: forward (5'-AAC AGT TCC TGA TTA ACC ACA AACC -3') and reverse (5'- GCC AGA AGT TCT TTT TCC AGT ACC -3') under the following PCR conditions, initial denaturation at $94^{\circ} \mathrm{C}$ for $4 \mathrm{~min}$., denaturation at $94^{\circ} \mathrm{C}$ for $45 \mathrm{sec}$, annealing at $51^{\circ} \mathrm{C}$ for $45 \mathrm{sec}$, extension at $72^{\circ} \mathrm{C}$ for $45 \mathrm{~s}$ and final extension at $72^{\circ} \mathrm{C}$ for $7 \mathrm{~min}$ were used for the confirmation of stable GUS gene integration and expression in putative regenerated transformed plantlets. Detection of stable nptII gene insertion conferring kanamycin resistance and presence of Agrobacterium contamination was done by using the protocol specified by Dangi et al. (2012) with slight modification in the initial denaturation temperature of $95^{\circ} \mathrm{C}$ for 3 min during PCR amplification.

The data on initial explants establishment, shoot bud formation, shoot proliferation and rooting were collected for four weeks. All the experiments were repeated thrice and the values were represented as Mean \pm standard error. In transformation experiments, one factor at a time was studied and effect on per cent GUS expression and transformation efficiency was recorded. Each experiment was repeated three times with 45 - 50 explants per replicate. GUS expression was calculated as percentage of infected explants showing GUS activity to the total number of explants infected. Transformation efficiency has been expressed as percentage of independently transformed transgenic plants (nptII PCR-positive plants) to the initial number of explants inoculated with Agrobacterium. Data were subjected to one-way analysis of variance (ANOVA) by Fischer's least significant difference $(\mathrm{p}<0.05)$ (Gomez and Gomez 1984).

\section{Results and Discussion}

Tissue culture methods to obtain regenerated plants were reported earlier by Bardar et al. (2014). The present communication elaborates upon the Agrobacterium-mediated genetic transformation in this plant.

In a preliminary experiment both super virulent Agrobacterium strains (LBA 4404 and EHA-105) with different plasmids were grown to standard OD600 1.0. Explants were subjected to bacterial infection for $30 \mathrm{~min}$. Amongt all, 
Agrobacterium strain EHA-105 harboring p35S-GUS-INT (Fig. 1) showed best GUS response $(80 \%)$ as well as maximum survival of the cocultivated explants. Hence it was selected to optimize basic essential conditions like bacterial density, infection time, cocultivation period, cocultivation temperature and concentration of AS during infection, co-cultivation for attaining maximum transformation efficiency.

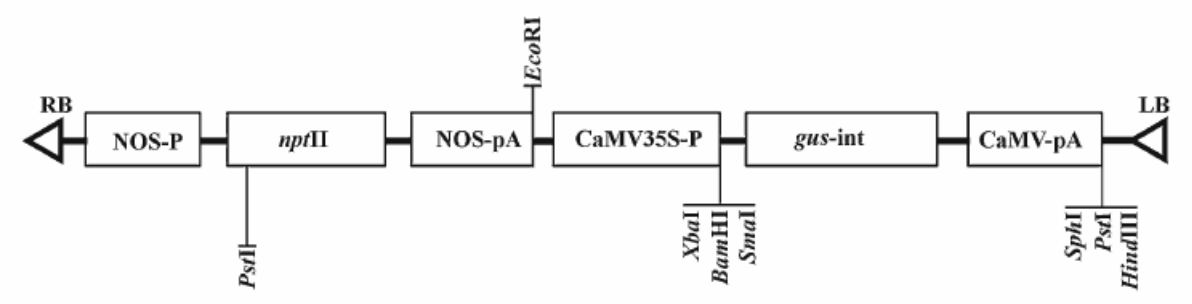

Fig. 1. Linear (partial) restriction map of the p35S-GUSINT T-DNA cassette. LB/RB left/ right border sequences, NOS-P/NOS-pA nopaline synthase promoter/terminator, CaMV 35S-P/CaMV-pA cauliflower mosaic virus 35S promoter/terminator (Vancanneyt et al. 1990).

Different concentrations of kanamycin $(0-100 \mathrm{mg} / \mathrm{l})$ were used to estimate the tolerance level of nodal explants. Higher doses of kanamycin showed reduced shoot regeneration in both the media. At $50 \mathrm{mg} / \mathrm{l}$ concentration of kanamycin, the percentage of regenerating explants in NRM and IRM was decreased to 30 and 22, respectively along with the development of albinic shoots. Hence, $50 \mathrm{mg} / \mathrm{l}$ concentration of kanamycin was used for further experiments (Fig. 2a).

Explants with active morphogenetic activity have a higher probability of Agrobacterium infection (Sangwan et al. 1992). Preculturing of explants for 5 and 6 days on IRM and NRM increased transient GUS expression to 40 and 25\%, respectively (Fig. 2b). Better percentage GUS response in lesser preculture period was obtained on IRM than NRM. Preculturing of explants resulted in increased morphogenic competency thereby leading to increased transformation efficiency also reported in Leucaena leucocepahala (Jube and Borthakur 2009) and Terminalia bellerica (Dangi et al. 2012).

Bacterial cell density as measured by the optical density (OD) of bacterial suspension is directly related to their cell mass or cell number (Dutt and Grosser 2009). Transient GUS activity is also influenced by density of bacterial inoculum used at the time of infection and during the infection period. At an optical density of $\geq 1.0$, Agrobacterium overgrowth was noticed and resulted in tissue necrosis. Maximum transient GUS activity $(80 \%)$ was observed at $\mathrm{OD}_{600}=0.8$ 
(Fig. 2c). Hence, optimized OD (0.8) was used with 30 min of infection time in further subsequent experiments. As duration of infection is raised above $30 \mathrm{~min}$
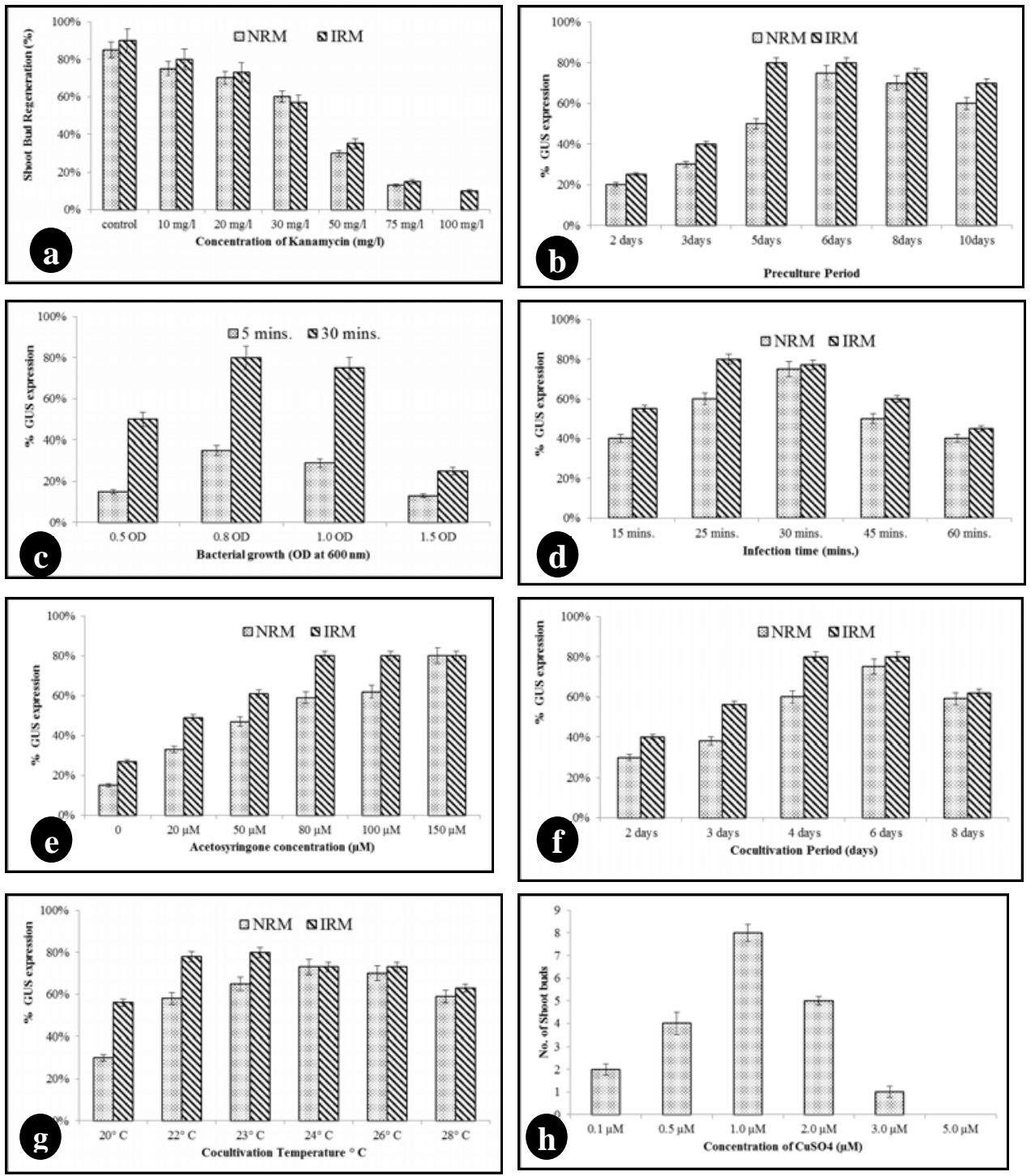

Fig. 2. Optimization of factors influencing percentage GUS expression in normal regeneration medium (NRM) and improved regeneration medium (IRM). (a) Effect of kanamycin on shoot regeneration from nodal explants of E. alba, (b) preculturing of nodal explants, (c) bacterial density (OD600), (d) infection time, (e) acetosyringone concentration, (f) cocultivation period, (g) cocultivation temperature and (h) Effect of copper sulphate. 
consistent browning of the target tissue was observed which is in conformity with similar previous studies reported in Terminalia bellerica (Dangi et al. 2012) and Eleusine coracana (Sharma et al. 2011) (Fig. 2d). Explants were wounded by sterilized needle prior to infection. Explants directly infected with Agrobacterium showed lower GUS expression than precultured explants.

Transient GUS activity was increased from 61 to $80 \%$ after adding $80 \mu \mathrm{M}$ AS in IRM compared to NRM where addition of $150 \mu \mathrm{M}$ AS was needed to obtain similar GUS expression (Fig. 2e). Less amount of AS was required in IRM compared to NRM for achieving similar GUS expression. This clearly indicates the better efficiency of IRM over NRM. AS is used to induce vir genes and enhance T-DNA transfer (Stachel et al. 1985). Omission of AS from infection and co-cultivation medium brings down the level of transient GUS expression. Present observations in both the media (IRM and NRM) are in agreement with similar previous reports in Eleusine coracana (Sharma et al. 2011). More amount of AS was needed at the time of infection compared to cocultivation for attaining optimum GUS response in both the media. Thus, $150 \mu \mathrm{M}$ AS was used during infection medium in all experiments. The presence of AS in co-cultivation medium was needed for stable GUS expression without affecting the growth of infected explants. An amount of $80 \mu \mathrm{M}$ of AS in co-culture medium proved to be more effective for stimulating the virulence system of bacterium and hence generating maximum GUS response.

The influence of a co-cultivation period on Agrobacterium mediated transformation has been reported for many plant species (Uranbey et al. 2005, Dangi et al. 2012). A co-cultivation period of 4 days and 6 days in the dark resulted in drastic increase in GUS expression from $56 \%$ to $80 \%$ and $60 \%$ to $75 \%$ in IRM and NRM respectively, thereby indicating the better efficacy of IRM over NRM (Fig. 2f). A co-cultivation period of more than 6 days leads to bacterial overgrowth and explant necrosis.

Perceptible differences in explant growth and regeneration response were observed on varying temperature conditions. Nodal explants co-cultivated at $23^{\circ} \mathrm{C}$ showed optimum transient GUS expression $80 \%$ in IRM comparable to $73 \%$ GUS expression in NRM at $24^{\circ} \mathrm{C}$ (Fig. $2 \mathrm{~g}$ ). This result further illustrates the credibility of IRM over NRM to attain maximum transformation frequency. However, Salas et al. (2001) stated that co-cultivation at $25^{\circ} \mathrm{C}$ appears beneficial for plant cell susceptibility to infection and for stable T-DNA insertion into the plant chromosomes.

Sharma et al. (2011) and Dangi et al. (2012) suggested that an elevated level of $\mathrm{CuSO}_{4}$ in the maintenance and plant regeneration medium improves explant growth and recovery of plantlets in Eleucine corcana and Terminalia bellerica 

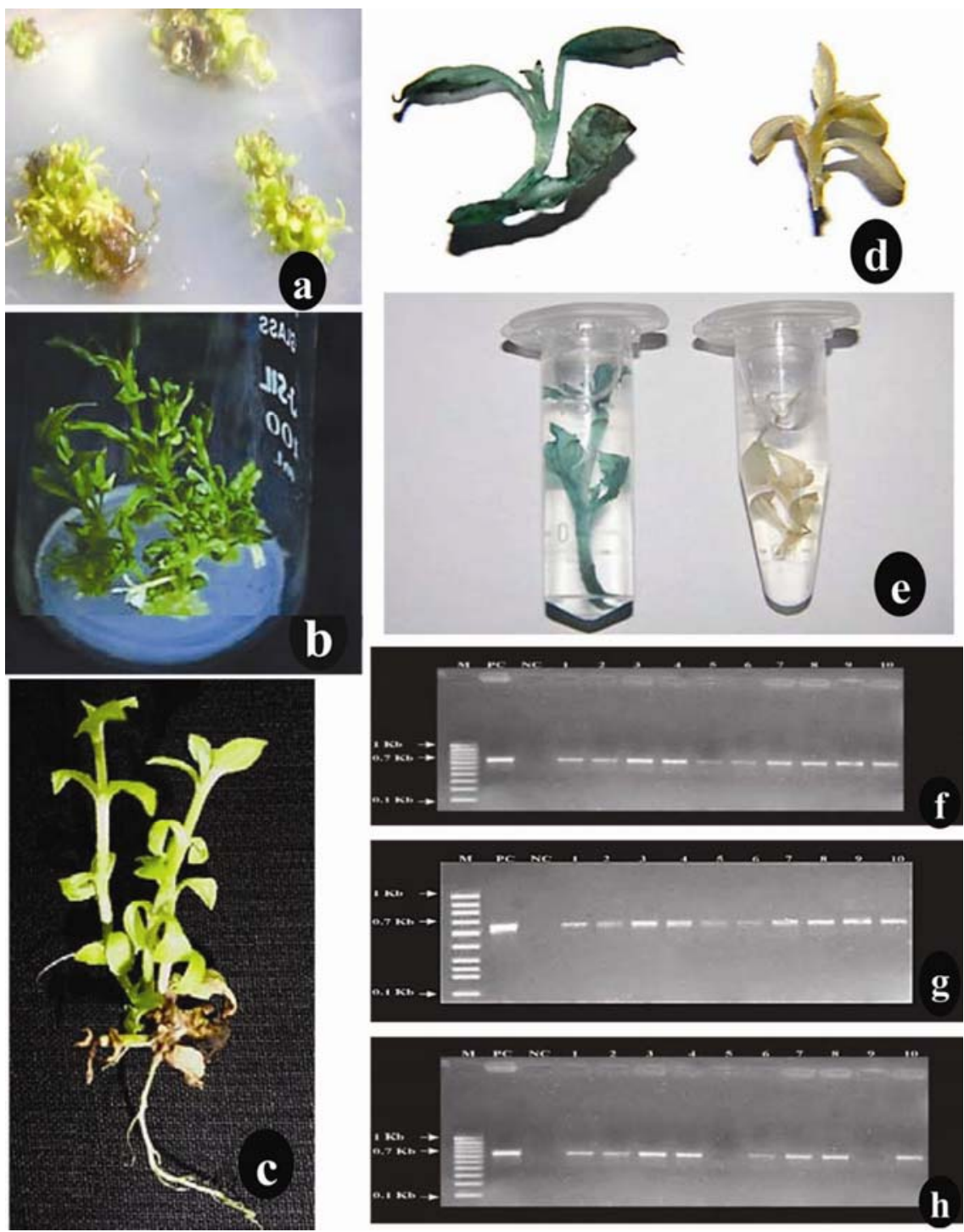

Fig. 3. (a) Origin of multiple kanamycin tolerant shoot buds from nodal explants cultured on improved regeneration medium. (b) Regeneration of green and albino plants on improved regeneration medium supplemented with kanamycin $(50 \mathrm{mg} / \mathrm{l})$ after 4 week of culture. (c) Rooted putative transgenic plant. (d, e) GUS staining of transgenic shoots (left) and nontransformed control (right). Molecular analysis of DNA isolated from primary transgenic plants. (f) nptII gene amplification (650 bp). (g) GUS A gene amplification (634 $\mathrm{bp}), \mathrm{M}$ - molecular marker, PC - positive control (p35S-GUS-INT plasmid DNA), NCnegative control (non transformed plant DNA), Lanes 1-10-putative transformants. (h). amplification of selectable marker gene nptII in T1 generation plantlets of Eclipta, Mmolecular marker, PC - positive control (plasmid DNA), NC - negative control (non transformed plant DNA), Lanes 1-10-transgenic plants of T1 generation. 
respectively. Our experimental reports are in accordance to them. Agrobacteriuminfected nodal explants cultured on IRM showed better shoot recovery compared to NRM (Fig. 2h).

Considering the optimized conditions, 200 nodal explants were co-cultivated and then cultured on IRM and NRM containing kanamycin (50 mg/l) (Fig. 3a) and cefotaxime $(325 \mathrm{mg} / \mathrm{l})$ for shoot regeneration. Putative transgenic shoot buds were selected and transferred onto fresh media containing the same concentrations of antibiotics for 15 days, until the shoots attained a height of $1.5-3.0 \mathrm{~cm}$ (Fig. 3b). After four cycles of selection, putative transgenic green healthy shoots were transferred to rooting medium containing full strength MS salts plus IBA $(1.0 \mathrm{mg} / \mathrm{l})$ and $3 \%$ sucrose (Fig. 3c). GUS staining of the shoots and leaf tissues displayed the stable and transient expression of npt II and gus $A$ in the transgenics (Fig. 3d, e). The putative transformed plantlets were subjected to hardening and acclimatization in green house.

Ten putative transformants were analyzed for the presence of nptII and gus A gene through PCR, and all gave the expected 650 and $634 \mathrm{bp}$ PCR products for the corresponding genes respectively (Fig. 3f, g). Agrobacterium contamination using 729 bp vir $C$ gene-specific primers was then checked for the positive plants. None of the samples showed amplification of vir $C$ gene. DNA isolated from seedlings of each T1 generation was subjected to PCR amplification with nptII specific primers. The results revealed that transgene was stably integrated and expressed in subsequent generation (Fig. 3h).

\section{Acknowledgments}

The first author (SB) thanks University Grants Commission (UGC), New Delhi for the award of Junior/Senior Research Fellowship (JRF/SRF).

\section{References}

Bardar S, Khurana-Kaul V, Kachhwaha S and Kothari SL (2014) Nutrient optimization for improved in vitro plant regeneration in Eclipta alba (L.) Hassk. and assessment of genetic fidelity using RAPD analysis. Plant Tissue Cult. Biotechnol. 24: 223-234.

Baskaran P and Jayabalan N (2005) An efficient micropropagation system for Eclipta alba - A valuable medicinal herb. In Vitro. Cell. Dev. Biol. Plant. 41: 532-539.

Borthakur M, Dutta K, Nath SC and Singh RS (2000) Micropropagation of Eclipta alba and Eupatorium adenophorum using a single step nodal cutting technique. Plant Cell Tiss. Org. Cult. 62: 239-242.

Dangi B, Kachhwaha S and Kothari SL (2012) Regeneration and Agrobacterium-mediated genetic transformation of Terminalia bellerica Roxb.: a multipurpose tree species. In Vitro. Cell. Dev. Biol. Plant 48: 304-312. 
Dhaka N and Kothari SL (2005) Micropropagation of Eclipta alba (L.) Hassk. - an important medicinal plant. In Vitro. Cell. Dev. Biol. Plant 41: 658-661.

Dutt M and Grosser JW (2009) Evaluation of parameters affecting Agrobacteriummediated transformation of citrus. Plant Cell Tiss. Org. Cult. 98: 331-340.

Franca SC, Bertoni BW and Pereira AMS (1995) Antihepatotoxic agent in micropropagated plantlets of Eclipta alba. Plant Cell Tiss. Org. Cult. 40: 297-299.

Gomez KA and Gomez AA (1984) Statistical procedures in agricultural research. Wiley, New York.

Jadhav VM, Thorat RM, Kadam VJ and Salaskar KP (2009) Chemical composition, pharmacological activities of Eclipta alba. J. Pharm. Res. 2: 1129-1231.

Jefferson RA (1987) Assaying chimeric genes in plants: the GUS gene fusion system. Plant Mol. Biol. Rep. 5: 387-405.

Jube S and Borthakur D (2009) Development of an Agrobacterium-mediated transformation protocol for the tree-legume Leucaena leucocephala using immature zygotic embryos. Plant Cell Tiss. Org. Cult. 96: 325-333.

Salas M, Park S, Srivatanakul M and Smith R (2001) Temperature influence on stable TDNA integration in plant cells. Plant Cell Rep. 20: 701-705.

Sangwan RS, Bourgeois Y, Brow S, Vasseur G and Sangwan-Norreel BS (1992) Characterization of competent cells and early events of Agrobacterium-mediated genetic transformation of Arabidopsis thaliana. Planta 188: 439-456.

Sharma M, Kothari-Chajer A, Jagga-Chugh S and Kothari SL (2011) Factors influencing Agrobacterium tumefaciens-mediated genetic transformation of Eleusine coracana (L.) Gaertn. Plant Cell Tiss. Org. Cult. 105: 93-104.

Singh SK, Rai MK and Sahoo L (2012) An improved and efficient micropropagation of Eclipta alba through transverse thin cell layer culture and assessment of clonal fidelity using RAPD analysis. Ind. Crops and Prod. 37: 328-333.

Stachel SE, Messens E, Van M and Zambryski P (1985) Identification of signal molecules produced by wounded plant cells that activate T-DNA transfer in Agrobacterium tumefaciens. Nature 318: 624-629.

Uranbey S, Sevimay CS, Kaya MD, İpek A, Sancak C, Başalma D, Er C and Özcan CS (2005) Influence of different co-cultivation temperatures, periods and media on Agrobacterium tumefaciens-mediated gene transfer. Biol. Plant 49: 53-57.

Vancanneyt G, Schmidt R, O'Connor-Sanchez A, Willmitzer L and Rocha-Sosa M (1990) Construction of an intron-containing marker gene:splicing of the intron in transgenic plants and its use in monitoring early events in Agrobacterium-mediated plant transformation. Mol. Gen. Genet. 220: 245-250.

Vincent JM (1970) A manual for the practical study of the root nodule bacteria. IBH hand book no. 15. Blackwell Scientific, Oxford. p. 72. 